\title{
Potencial de Controle da Erva-de-Santa-Maria sobre Pratylenchus brachyurus
}

\author{
Alexandre F.S. Mello, Andressa C.Z. Machado \& Mário M. Inomoto \\ Departamento de Entomologia, Fitopatologia e Zoologia Agrícola, ESALQ, Universidade de São Paulo, \\ Cx. Postal 9, CEP 13418-900, Piracicaba, SP, e-mail: afsmello@gmail.com
}

(Aceito para publicação em 16/10/2006)

Autor para correspondência: Alexandre Furtado Silveira Mello

MELLO, A.F.S., MACHADO, A.C.Z. \& INOMOTO, M.M. Potencial de controle da erva-de-Santa-Maria sobre Pratylenchus brachyurus. Fitopatologia Brasileira 31:513-516. 2006.

\section{RESUMO}

O emprego de plantas antogônicas tem sido uma alternativa no controle de fitonematóides. O efeito da erva-deSanta-Maria (ESM) sobre a população de Pratylenchus brachyurus foi avaliado em teste in vitro e em dois experimentos em condições de casa de vegetação. No teste in vitro, utilizou-se extrato de ESM em quatro concentrações (20;2; 0,2 e 0,02\%), em suspensões contendo 500 exemplares de P. brachyurus. Após 48 h, os nematóides vivos foram coletados e contados. Verificou-se que a ESM possui ação nematicida, sendo observada maior mortalidade de juvenis de $P$. brachyurus quando comparada com o controle químico (aldicarb). Nos experimentos em casa de vegetação, plantas de ESM e soja foram inoculadas com 1.500 e 5.000 nematóides, respectivamente, e, após 45 dias, a parte aérea (PA) foi incorporada ao solo, seguindo-se os seguintes tratamentos: incorporação da PA da ESM; incorporação da PA da soja; e sem incorporação da PA. Após um mês, cada vaso recebeu uma planta de soja, para atuar como indicador biológico de parasitismo. Após 45 dias, avaliou-se a população final do nematóide presente nas raízes de soja e no solo e as massas seca da PA e fresca de raízes da soja. Houve redução da população do nematóide nos tratamentos com ESM, mas foi observada fitotoxidez em plantas de soja.

Palavras-chave adicionais: controle alternativo, controle cultural, nematóide das lesões, controle in vitro.

\begin{abstract}
Potential Control of Pratylenchus brachyurus by Chenopodium ambrosioides

Antagonist plants have been used as an alternative to control plant-parasitic nematodes. One in vitro assay and two greenhouse experiments were carried out to evaluate the effects of Mexican-tea (Chenopodium ambrosioides) on the control of Pratylenchus brachyurus. In the in vitro test an extract of Mexican-tea was tested at four concentrations (20; 2; 0.2 and $0.02 \%$ ), in suspensions containing 500 exemplars of $P$. brachyurus. After $48 \mathrm{~h}$, living nematodes were collected and counted. A nematicidal action of Mexican-tea was observed by higher juvenile mortality in comparison with chemical control (aldicarb). In greenhouse experiments, 1 and 2, the Mexican-tea and soybean plants were inoculated with 1,500 and 5,000 P. brachyurus, respectively. Forty-five days later, plant shoots were incorporated in soil, as follows: shoots of Mexican-tea, were incorporated; shoots of soybean were incorporated; and plant shoots were not incorporated. One month later, each pot received one soybean plant, to act as a biological indicator of parasitism. At the end of experimental period (45 days later) the final nematode population was estimated by counting the nematodes extracted from soybean roots and soil, and data were collected of fresh root weight and shoot dry weight. Mexican-tea reduced the nematode population, although soybean plants had been affected by phytotoxicity.
\end{abstract}

Additional keywords: Alternative control, cultural practice, lesion nematode, in vitro control.

Nos últimos anos, devido ao fato da sociedade ter priorizado aspectos ambientais, muitas pesquisas têm sido direcionadas para descoberta de novas substâncias bioativas que possam ser empregadas no manejo integrado de pragas e doenças de plantas, com menos efeitos negativos ao meio ambiente (Castro, 1989). Como resultado, observa-se que os métodos culturais como rotação de culturas e emprego de plantas antogônicas têm tido destaque dentre as novas alternativas recomendadas para o controle de fitonematóides.

O emprego de plantas com efeito antagônico a fitonematóides, utilizadas em plantio intercalado, consorciado ou em rotação, constitui um dos métodos mais promissores no controle desses organismos. O efeito de tais plantas é exercido pelos exsudatos radiculares tóxicos e/ou por mecanismos de resistência, que impedem o desenvolvimento e reprodução do nematóide no sistema radicular (Peacock, 1959). Além disso, a decomposição da matéria orgânica incorporada favorece a proliferação de inimigos naturais, além de liberar substâncias com efeito nematicida (Badra et al., 1979). Algumas plantas contêm na parte aérea compostos nematicidas pré-formados, que podem contribuir para o controle de nematóides após a 
incorporação, além de atuarem contra patógenos de solo (Rodríguez-Kábana et al., 1994). As atividades de seus metabólitos têm papel ecológico freqüentemente associado com a sobrevivência e competição com outros organismos (Harbourne, 1988). Algumas dessas substâncias têm sido purificadas e identificadas, caso do ácido asparagúsico, da 2,5-(diidroximetil)-3,4-diidroxipirrolidina, da bursaermina, do $\alpha$-tertienil e da L-dopa, que foram isoladas de extratos das plantas Aspargus officinalis L., Lonchocarpus costaricensis Pittier, Bupleurum salicifolium R. Brown, Tagetes spp. e Mucuna aterrima Merr., respectivamente (González et al., 1994; Barcelos et al., 1997).

Alguns trabalhos já evidenciaram redução da população de nematóides no solo com a utilização de extratos vegetais (Costa et al., 2000), óleos essenciais (Leela et al., 1992) e a própria ação antagônica de algumas espécies vegetais sobre a população de nematóides (Moura et al., 1990).

Portanto, existem várias plantas citadas na literatura que possuem efeito antagônico a importantes espécies de fitonematóides, seja pela ação direta da planta, diminuindo ou impedindo a multiplicação dos nematóides, seja pela ação indireta, por meio da aplicação de extratos dessas plantas ou seus produtos de decomposição. Esses relatos justificam novos estudos com diferentes espécies de plantas que poderiam ter efeito nematicida, auxiliando o difícil manejo desses organismos.

O objetivo do presente trabalho foi avaliar o efeito da erva-de-Santa-Maria (Chenopodium ambrosioides L.) no controle de Pratylenchus brachyurus (Godfrey) Filipjev \& Schuurmans Stekhoven em testes in vitro e em condições de casa-de- vegetação.

\section{Obtenção do inóculo}

Foi utilizada uma população de $P$. brachyurus obtida originalmente de raízes de quiabeiro (Abelmoschus esculentus Moench), coletadas no do município de Seropédica, RJ. Essa população foi obtida a partir de fêmeas desinfestadas superficialmente com o antibiótico ampicilina, e mantida em plantas de quiabeiro, no Setor de Nematologia do Departamento de Entomologia, Fitopatologia e Zoologia Agrícola da ESALQ/ USP, em Piracicaba, São Paulo.

Para a obtenção do inóculo, raízes de quiabeiro foram trituradas em liqüidificador e juvenis misturados a fêmeas do nematóide foram obtidos pelo método de Baermann modificado para recipiente raso. Na suspensão assim obtida, foi estimado, sob microscópio óptico e usando-se lâmina de Peters, o número de espécimes de $P$. brachyurus por mililitro.

\section{I - Avaliação do extrato da erva-de-Santa-Maria na mortalidade de Pratylenchus brachyurus in vitro}

$\mathrm{O}$ extrato de erva-de-Santa-Maria (ESM), $C$. ambrosioides, utilizado no ensaio in vitro foi preparado de duas maneiras distintas. Na primeira, foram misturados 100 gramas de parte aérea de plantas de ESM, com 60 dias de idade, a 500 $\mathrm{ml}$ de água fervente $\left(100^{\circ} \mathrm{C}\right)$ e triturados em liquidificador por 40 segundos. Na seqüência, o extrato foi transferido para tubo
Falcon, onde foi mantido por $24 \mathrm{~h}$ em temperatura ambiente $\left(25^{\circ} \mathrm{C}\right)$ (extrato de um dia). Na segunda metodologia adotada, foi utilizado o mesmo procedimento da primeira, dispensando o repouso de $24 \mathrm{~h}$ (extrato fresco).

Foram utilizadas quatro concentrações dos extratos fresco e de um dia $(20,2,0,2$ e $0,02 \%)$ e os controles 50 ppm aldicarb e água destilada, em suspensões contendo 500 exemplares de $P$. brachyurus, num total de cinco repetições por tratamento. Após $48 \mathrm{~h}$, os nematóides foram coletados em uma peneira de malha 500 meshes (abertura de 0,025 $\mathrm{mm})$ e recolhidos pela lavagem em água. Em seguida, os nematóides foram colocados sobre folha de papel extra-fino, em folhas duplas, em suporte de tela de plástico, montado em vidros de relógio do tipo siracusa, contendo água destilada. Os nematóides que atravessaram o papel e ficaram retidos na siracusa foram considerados vivos. Após $48 \mathrm{~h}$, foi realizada a coleta dos nematóides, seguida da contagem dos mesmos.

O delineamento estatístico foi do tipo inteiramente ao acaso onde a variável analisada foi a sobrevivência do nematóide. Os dados obtidos foram submetidos à análise de variância, utilizando o software SANEST, desenvolvido pelo Departamento de Matemática e Estatística da ESALQ/USP.

\section{II - Efeito da incorporação da erva-de-Santa-Maria no controle de Pratylenchus brachyurus em casa-de- vegetação}

A partir dos resultados encontrados no teste in vitro, foram instalados dois experimentos em casa-de-vegetação com o objetivo de verificar se o efeito no controle de $P$. brachyurus se daria também com a incorporação da parte aérea da ESM.

\section{Preparo das plantas e inoculação}

Foram realizados dois experimentos em casa-devegetação, em épocas distintas, visando determinar o efeito da ESM no controle de P. brachyurus. Para tal, soja (Glycine max Merrill) cv. Cristalina e ESM foram semeadas em vasos plásticos de $1.000 \mathrm{ml}$ de capacidade, contendo solo autoclavado. Quando as plantas de soja apresentavam duas folhas verdadeiras completamente desenvolvidas e as de ESM $15 \mathrm{~cm}$ de altura (as plantas que haviam ultrapassado esse limite foram podadas, para uniformização do experimento), foram inoculadas com suspensão contendo 5.000 e $1.500 P$. brachyurus por planta, respectivamente.

Após 45 dias da inoculação, a parte aérea das plantas foi cortada, triturada e incorporada ao solo, junto com as raízes, de acordo com os seguintes tratamentos: a) 21 vasos com plantas de soja (sete vasos sem parte aérea, sete vasos com a parte aérea da soja e sete vasos com a parte aérea da ESM); b) 21 vasos com plantas de ESM (sete vasos sem parte aérea, sete vasos com a parte aérea da soja e sete vasos com a parte aérea da ESM).

Após um mês, cada vaso recebeu uma planta de soja, para ser avaliada a população do nematóide. As plantas permaneceram durante todo o período experimental em casade- vegetação dotada de sistema de refrigeração, e regulada para entrar em funcionamento sempre que a temperatura em seu interior atingisse $31^{\circ} \mathrm{C}$. 
Potencial de controle da erva-de-santa-maria sobre Pratylenchus brachyurus...

A avaliação foi realizada 47 dias após, pela extração dos nematóides das raízes e do solo pelos métodos de Coolen \& D'Herde (1972) e Jenkins (1964), respectivamente, e posterior contagem dos nematóides extraídos em microscópio óptico, com auxílio de lâmina de Peters. A variável analisada foi o fator de reprodução $(\mathrm{FR}=\mathrm{Pf} / \mathrm{Pi})$, sendo $\mathrm{Pf}$ a população final de nematóides e Pi a população inicial. Além disso, foram coletados dados de massa seca da parte aérea das plantas e massa fresca de raízes.

$\mathrm{O}$ delineamento experimental foi do tipo inteiramente casualizado, em fatorial $2 \times 3$, com os fatores plantio inicial (soja e ESM) e parte aérea (soja, ESM e sem incorporação da parte aérea) e sete repetições, em ambos os experimentos. Cada repetição foi representada por um recipiente contendo uma planta. Os dados foram submetidos à análise de variância, seguindo-se o mesmo esquema do experimento anterior.

$\mathrm{O}$ teste in vitro mostrou que o extrato de ESM possui ação nematicida quando estocado por $24 \mathrm{~h}$ e nas concentrações de 20 e $2 \%$. O extrato fresco não mostrou efeito nematicida, demonstrando que a incubação de 24 horas é essencial para liberação de substâncias letais a $P$. brachyurus (Tabela 1). Nogueira et al. (1997) já haviam observado efeito antagônico em teste in vitro do extrato de ESM a Meloidogyne incognita (Kofoid \& White) Chitwood raça 3. Nesta pesquisa, verificouse que ESM não é hospedeira de P. brachyurus. Segundo Moura et al. (1990), ESM não permitiu a reprodução de $M$. incognita e M. javanica (Treub) Chitwood. Esse é um fato bastante importante, pois amplia as opções de espécies de plantas que podem ser utilizadas em áreas com infestações mistas de $M$. incognita e $P$. brachyurus, fato que ocorre com freqüência em algodoais, e $M$. javanica e P. brachyurus, muito comum em campos produtores de soja, já que poucas plantas citadas na literatura, como Crotalaria spectabilis Roth., apresentam a mesma reação de ESM (Silva et al., 1989).

Foi observada fitotoxidez em plantas de soja desenvolvidas onde havia sido cultivada ESM e, posteriormente, incorporada a parte aérea, tanto da ESM quanto da própria soja, sendo evidenciada a síndrome por amarelecimento generalizado. O plantio inicial de ESM reduziu a massa seca da parte aerea do plantio subsequente de soja em cerca de $38 \%$, quando comparado com o tratamento que recebeu soja na mesma etapa. Os mesmos
TABELA 1 - Número de nematóides vivos coletados 48 h após o tratamento com os extratos fresco e de um dia ( $24 \mathrm{~h})$ da ervade-Santa-Maria e os controles positivo (água destilada) e negativo (aldicarb a $50 \mathrm{ppm}$ )

\begin{tabular}{lc}
\hline \hline Tratamento & Número de nematóides vivos \\
\hline Água destilada & $109,6 \mathrm{cbc}$ \\
Extrato fresco $(20 \%)$ & $131,4 \mathrm{abc}$ \\
Extrato fresco $(2 \%)$ & $149 \mathrm{abc}$ \\
Extrato fresco $(0,2 \%)$ & $163,2 \mathrm{bc}$ \\
Extrato fresco $(0,02 \%)$ & $63,6 \mathrm{a}$ \\
Extrato $24 \mathrm{~h}(20 \%)$ & $68,4 \mathrm{a}$ \\
Extrato $24 \mathrm{~h}(2 \%)$ & $93,8 \mathrm{abc}$ \\
Extrato $24 \mathrm{~h}(0,2 \%)$ & $124,4 \mathrm{abc}$ \\
Extrato $24 \mathrm{~h}(0,02 \%)$ & $153,2 \mathrm{abc}$
\end{tabular}

Médias seguidas de mesma letra não diferem entre si pelo teste de Tukey a $5 \%$ de probabilidade.

efeitos não foram observados quando se cultivou soja antes da incorporação da parte aérea das plantas, indicando que a raiz da erva-de-Santa-Maria pode conter compostos tóxicos à cultura da soja. Tal fato tornou-se um inconveniente para a utilização da erva-de-Santa-Maria em larga escala em áreas infestadas por fitonematóides, uma vez que pode reduzir significativamente a produtividade de plantas que sejam cultivadas após incorporação e/ou cultivo, trazendo prejuízos ao agricultor.

A comparação dos dados dos dois experimentos mostrou equivalência de resultados e por isso apenas serão apresentados os dados do experimento 1. A incorporação da parte aérea da soja e da ESM promoveu a diminuição da população do nematóide no solo (Tabela 2). Quando se

TABELA 2 - Massa seca da parte aérea (MSPA), massa fresca de raízes (MFR) de plantas de soja (em gramas) e fator de reprodução $(\mathrm{FR}=\mathrm{Pf} / \mathrm{Pi}) \mathrm{de}$ Pratylenchus brachyurus em plantas de soja, após plantio inicial (Plant.) com soja ou erva-de-Santa-Maria (ESM) e posterior incorporação ou não (Sem PA) da parte aérea das plantas (Inc.)

\begin{tabular}{|c|c|c|c|c|c|c|}
\hline & \multicolumn{2}{|c|}{ MSPA } & \multicolumn{2}{|c|}{ MFR } & \multicolumn{2}{|c|}{ FR } \\
\hline $\begin{array}{l}\text { Plant. } \\
\text { Inc. }\end{array}$ & Soja & ESM & Soja & ESM & Soja & ESM \\
\hline Soja & $2,78 \mathrm{aB}$ & $1,73 \mathrm{bB}$ & $9,07 \mathrm{aA}$ & $6,69 \mathrm{aA}$ & $0,27 \mathrm{aB}$ & $0,07 \mathrm{bA}$ \\
\hline ESM & $4,04 \mathrm{aA}$ & $2,11 \mathrm{bB}$ & $9,51 \mathrm{aA}$ & $8,08 \mathrm{aA}$ & $0,37 \mathrm{aB}$ & $0,05 \mathrm{bA}$ \\
\hline Sem PA & $2,91 \mathrm{aB}$ & $3,26 \mathrm{aA}$ & $9,96 \mathrm{aA}$ & $11,33 \mathrm{aA}$ & $1,21 \mathrm{aA}$ & $0,02 \mathrm{bA}$ \\
\hline
\end{tabular}

Médias seguidas de mesma letra minúscula na linha e maiúscula na coluna não diferem entre si pelo teste de Tukey a $5 \%$ de probabilidade. 
incorporou soja depois de ESM, o fator de multiplicação foi baixo. Entretanto, não houve diferença nas populações do nematóide quando se comparou as incorporações de soja ou ESM depois do plantio de soja (Tabela 2). A incorporação de ESM ou soja não causou efeito adverso na massa fresca de raízes, mas na massa seca da parte aérea sim. Tal efeito pode ser explicado pela produção de substâncias tóxicas e/ou com efeito alelopático à cultura da soja, que ocorre com a decomposição da matéria orgânica incorporada. Nos experimentos, foram utilizados vasos pequenos, contendo pouco solo (cerca de 1 litro de solo), onde a incorporação da parte aérea das plantas maximizou o efeito natural de eliminação de compostos tóxicos pela decomposição da matéria orgânica. Efeito adverso semelhante já foi observado anteriormente por Costa et al. (2000), que observaram que a aplicação de extratos de C. ambrosioides e Ricinus communis L. causou fitotoxicidade a plantas de tomateiro.

Portanto, a ESM apresentou potencial para controle de $P$. brachyurus, tanto como opção de rotação de cultura quanto pela aplicação de extrato de um dia. Entretanto, os resultados mostraram que a ESM é mais útil no controle de $P$. brachyurus quando incorporada ao solo do que quando utilizada em rotação de culturas. Por outro lado, são necessários estudos para verificar se os efeitos fitotóxicos das raízes e da parte aérea da ESM observados em casa-devegetação também se manifestam em condições de campo.

\section{AGRADECIMENTOS}

Os autores agradecem à FAPESP e ao CNPq pela concessão de bolsas.

\section{REFERÊNCIAS BIBLIOGRÁFICAS}

BADRA, T., SALEH, M.A. \& OTEIFA, B.A. Nematicidal activity and composition of some organic fertilizers and amendments. Revue Nématologie 2:29-36. 1979.

BARCELOS, F.F., BARBOSA, L.C.A., DEMUNER, A.J., SANTOS, M.A. \& WERLANG, R.C. Atividade nematicida de constituintes químicos de Mucuna aterrima em Heterodera glycines. XX Congresso Brasileiro de Nematologia, Gramado, Resumos, p.64. 1997.
CASTRO, A.G. Defensivos agrícolas como um fator ecológico. EMBRAPA-CNPDA (Documento 6), Jaguariúna, 20 p. 1989.

COOLEN, W.A. \& D'HERDE, C.J. A method for the quantitative extraction of nematodes from plant tissue. Ghent, Bélgica. State Nematology and Entomology Research Station, 1972. 77p.

COSTA, M.J.N., CAMPOS, V.P., PFENNING, L.H. \& OLIVEIRA, D.F. Patogenicidade e reprodução de Meloidogyne incognita em tomateiros (Lycopersicon esculentum) com aplicação de filtrados fúngicos ou extratos de plantas e de estercos animais. Nematologia Brasileira 24:219-226. 2000.

GONZÁLEZ, J.A., BRAUM, A.E., REYES, R.E. \& RAVELO, A.G. Inhibition of potato cyst nematode hatch by lignans from Bupleurum salicifolium (Umbeliferae). Journal of Chemical Ecology 20:517-524. 1994.

HARBOURNE, J.B. (Ed.) Introduction to Ecological Biochemistry. London. Academic Press. 1988.

JENKINS, W.R. A rapid centrifugal-flotation technique for separating nematodes from soil. Plant Disease Reporter 48:692. 1964.

LEELA, N.K., KHAN, R.M., REDDY, P.P. \& NIDIRY, E.S.J. Nematicidal activity of essencial oils of Pelargonium graveolens against the root-knot nematode Meloidogyne incognita. Nematologia Mediterranea 20:57-58. 1992.

MOURA, R.M., OLIVEIRA REGIS, E.M. \& MOURA, A.M. Reactions of ten plant species, some producers of essential oils, in relation to Meloidogyne incognita race 1 and M.javanica parasitism in mixed population. Nematologia Brasileira 14:39-44. 1990.

NOGUEIRA, M.A., OLIVEIRA, J.S., FERRAZ, S. \& SANTOS, M.A. The activity of Mucuna deeringiana and Chenopodium ambrosioides crude extracts upon Meloidogyne incognita race 3. Revista Ceres 44:124-127. 1997.

PEACOCK, F.C. The development of a technique for studying the host-parasite relationships of the root-knot nematode Meloiodgyne incognita under controlled conditions. Nematologica 4:43-55. 1959.

RODRÍGUEZ-KÁBANA， R., KOKALIS-BURELLE, N., ROBERTSON, D.G., KING, P.S. \& WELLS, L.W. Rotations with coastal bermudagrass, cotton, and bahiagrass for management of Meloidogyne arenaria and southern blight in peanut. Journal of Nematology 26:665-668. 1994.

SILVA, G.S., FERRAZ, S. \& MAIA, J.M. Resistência de espécies de Crotalaria a Pratylenchus brachyurus e P. zeae. Nematologia Brasileira 13:81-86. 1989. 